\title{
Erratum to: The Effect of Laparoscopic Sleeve Gastrectomy with Concomitant Hiatal Hernia Repair on Gastroesophageal Reflux Disease in the Morbidly Obese
}

\author{
Kamran Samakar $^{1}$ - Travis J. McKenzie ${ }^{2}$ - Ali Tavakkoli ${ }^{3}$ - Ashley H. Vernon ${ }^{3}$. \\ Malcolm K. Robinson ${ }^{3} \cdot$ Scott A. Shikora ${ }^{3}$
}

Published online: 21 September 2015

(C) Springer Science+Business Media New York 2015

Erratum to: OBES SURG

DOI 10.1007/s11695-015-1737-0

There is an error in the results section of the abstract. The sentence which currently reads "Preoperatively, 34.6\% $(n=26)$ of patients reported subjective symptoms of reflux and/or required daily antisecretory therapy." should read: "Preoperatively, 44.8\% $(\mathrm{n}=26)$ of patients reported subjective symptoms of reflux and/or required daily antisecretory therapy."

The online version of the original article can be found at http://dx.doi.org/ 10.1007/s11695-015-1737-0.

Kamran Samakar

kamran.samakar@med.usc.edu

Travis J. McKenzie

mckenzie.travis@mayo.edu

Ali Tavakkoli

atavakkoli@partners.org

Ashley H. Vernon

avernon@partners.org

Malcolm K. Robinson

mkrobinson@partners.org

Scott A. Shikora

sshikora@partners.org

1 Division of Upper GI and General Surgery, University of Southern California, 1510 San Pablo Street, Los Angeles, CA 90033, USA

2 Department of General Surgery, Mayo Clinic, Rochester, MN, USA

3 Department of General and GI Surgery, Brigham and Women's Hospital, Boston, MA, USA 